\title{
ANXIETY \& DEPRESSION; \\ PREVALENCE AMONG THE STUDENTS OF PEOPLES UNIVERSITY OF MEDICAL AND HEALTH SCIENCES FOR WOMEN NAWABSHAH: A RURAL PERSPECTIVE
}

1. Senior Registrar Liaquat University of Medical \& Health Sciences Jamshoro, Sindh

2. Associate Professor of Neurology Peoples University of Medical \& Health Sciences for Women Nawabshah, Sindh

3. Assistant Professor of Psychiatry PUMHSW, Nawabshah, Sindh.

4. Assistant Professor of Neurology PUMHSW, Nawabshah, Sindh.

Correspondence Address:

Dr. Muslim Ali Lakhiar

Senior Registrar Neurology

LUMHS, Jamshoro

drmuslimali@yahoo.com

Article received on: 25/10/2016

Accepted for publication: 05/02/2017

Received after proof reading: 06/04/2017

\section{Dr. Muslim Ali Lakhiar ${ }^{1}$, Dr. Shaheen Ahmed Mughal' ${ }^{2}$, Dr. Motti Ram Bhattia ${ }^{3}$, Dr. Awais Bashir larik ${ }^{4}$}

ABSTRACT... Objectives: To determine the prevalence of Anxiety \& Depression among the students of Peoples University of Medical and Health Sciences for Women Nawabshah and to ascertain the relative impact of rural environment. Study Design: Cross-sectional, questionnairebased survey. Setting: Peoples University of Medical \& Health Sciences for Women (PUMHSW), Nawabshah. Methods: This is the only medical university for female students located in the interior of Sindh. The students belong to various rural districts of the Sindh Province. After taking verbal consent the questionnaire of the Aga Khan University Anxiety \& Depression Scale (AKUADS) Urdu version was administered to the students from first year to the final year. A score of $\geq 20$ on AKUADS was used as a cut-off for the presence of anxiety and depressive symptoms. The data collected was tabulated and analyzed using SPSS 19. Results: Out of a total of 1035 students in a five year MBBS program at PUMHSW, 851 students responded \&agreed to participate. The response rate was $82.2 \%$. According to the AKUADS $66.7 \%$ of female students were found to have anxiety and depression. Majority of the students were originally from various rural districts of Sindh. The Prevalence of anxiety and depression among students of $1^{\text {st }}$ year, $2^{\text {nd }}$ year, $3^{\text {rd }}$ year, $4^{\text {th }}$ year and $5^{\text {th }}$ year was $71.1 \%, 76.9 \%, 53.7 \%, 70.7 \%$ and $63.6 \%$ respectively. It was significantly higher in $1^{\text {st }}$ year and $2^{\text {nd }}$ year as compared to $3^{\text {rd }}, 4^{\text {th }}$ and $5^{\text {th }}$ year $(p<0.05)$ students. Those aged $<21$ years were most vulnerable $(p<0.025)$. Marital status and either living at home or in hostel was statistically not significant $(p<0.922$ and $p<0.596$ respectively). None of the students were using antidepressants nor they ever visited a psychiatrist before. All students were attending lectures and hospital postings regularly. Conclusion: Our study indicates that a high proportion of female medical students particularly those belonging to the rural areas of Sindh suffer from anxiety and depression during the course of their medical education. Female gender, younger age and the rural environment appears to have a profound negative impact. The overall prevailing situation warrants a proper psychiatric evaluation of these students so that remedial measures can be undertaken whenever necessary.

Key words: $\quad$ Anxiety, Depression, Rural, Female Gender.

Article Citation: Lakhiar MA, Mughal SA, Bhattia MR, Larik AB. Anxiety \& depression; prevalence among the students of peoples university of medical and health sciences for women Nawabshah: a rural perspective. Professional Med J 2017;24(4):589-595. DOI: 10.17957/TPMJ/17.3698

\section{INTRODUCTION}

Anxietyand depressionarecommon psychological problems in Pakistan. The prevalence of anxiety and depression in our local population range from $29-66 \%$ for women and $10-33 \%$ for men. ${ }^{1}$ National ${ }^{2-6}$ as well as International ${ }^{7-9}$ studies have reported high prevalence of anxiety and depression among medical students. Whether this represent a general trend of increasing incidence of these disorders in a given population or is it more specific for certain professions like medical education is not clear. Some studies suggest that due to academic stress medical students are at a higher risk of developing physical and mental health problems as compared to non-medical students. ${ }^{10}$ However, other studies do not seem to agree to this and reported higher prevalence of anxiety and depression among students of other professions like Pharmacy ${ }^{11}$ and law ${ }^{12}$ compared to medical students. Yet there are studies reporting noremarkable differences in this respect. ${ }^{13}$ These ambiguities seem to favor a view that merely the type of education is not the major determinant for developing these disorders. There is a need for exploring other contributing factors besides implicating the professional-related academic 
stress. One avenue would be to look at the medical students who are pursuing advanced studies in less advanced areas such as interior of Sindh. For female students in particular religious and cultural values may be more stringent in rural areas than in the urban areas. Thus the female gender and the influence of rural environment that may also require wearing a hijab or a veil (burqa) while dealing with day to day matters may be challenging for a smooth academic pursuits. Furthermore, a male dominant faculty as well as the male dominant administrative setup may not be conducive for them and instead may create certain social and cultural barriers. These issues, in part, may play a significant role in the development of anxiety and depression particularly in the female medical students. It is of note that the previous local studies were done in medical universities situated in the major urban cities like Karachi ${ }^{3,5}$, Lahore ${ }^{2,4}$, Islamabad. ${ }^{14}$ No such study has been carried out in female medical students having a predominant rural background. The purpose of this study was to determine the prevalence of anxiety and depression among the female students of a medical university located in the interior of Sindh and to ascertain the relative impact of the rural environment.

\section{METHODOLOGY}

This was a cross-sectional, questionnaire-based survey carried out at Peoples University of Medical \& Health Sciences for Women (PUMHSW), Nawabshah. This is the only medical University for female students located in the interior of Sindh. The study was approved by the Ethical Committee of the University. All the students were explained about the nature of the study. Verbal consent was taken before distributing the questionnaires. The questionnaire used to assess anxiety and depression level was the AKUADS. ${ }^{15,16}$ A score of $\geq 20$ on AKUADS was used as a cut-off for the presence of anxiety and depressive symptoms. AKUAD score of 20 as a cut-off is $66 \%$ sensitive and $79 \%$ specific and has $83 \%$ positive predictive value and $60 \%$ negative predictive value. ${ }^{17}$ The AKUAD questionnaire Urdu version developed for the local population was administered to the student who were present at the time of survey. The study was based on a sample of convenience. To provide confidentiality we asked the students to write their roll numbers instead of names. Data collection spanned over the month of September 2015. The data was collected from Lecture halls, demonstration classes \& Hostels. Statistical analysis was done by using SPSS version 19.0. Descriptive statistics were calculated for variables like age, residence and marital status. Frequencies along with percentages were calculated for categorical variables like presence of anxiety and depression amongst medical students. A chi-square test was applied at $5 \%$ level of significance $(a=0.05)$ to look for any existing association between prevalence of anxiety \& depression and socio-demographic and educational characteristics.

\section{RESULTS}

A total of 1035 female medical students were registered at PUMHS Nawabshah. Out of these 851 medical students from first year to final year MBBS filled and returned the Questionnaire. The overall response rate was $82.2 \%$. The age ranged from 18 to 25 years and mean age was 21.06 with standard deviation of 1.836. Among all $744(87.4 \%)$ were living in hostels and 107 $(12.6 \%)$ were residing at their homes. Out of 851 students 768 (90.2\%) were single and 83 $(9.8 \%)$ were married. The basic demographic data of all students is shown in Table-I. Majority of the students were originally from different rural districts of Sindh. The prevalence of anxiety and depression among the respondent female medical students based on AKUAD Scale was $66.7 \%$ as shown in (Figure-1). The prevalence of anxiety and depression in students of first, second, third, fourth and fifth year medical students was $71.1 \%$, $76.9 .6 \%, 53.7 \%, 70.7 \%$ and $63.6 \%$ respectively (Figure-2). The AKUADS score ranged from 0 to 94 and mean was 28 as shown in Table-Il. There was a significant association between the prevalence of anxiety and depression and the respective year of medical college $(p<0.001)$ Table-Ill. It was also noted that age less than 21 year $(p<0.025)$ had a significant association with anxiety and depression as shown in Table-IV. Whether living at home or in hostel $(p>0.596)$ and marital 
status ( $p>0.922)$ did not significantly affect the prevalence rates Table-V\&VI respectively. None of the students were using antidepressants. None has ever visited a psychiatrist before. All the students were attending lectures and hospital postings regularly.

\begin{tabular}{|c|c|c|}
\hline \multicolumn{2}{|c|}{ Sample Size } & 851 \\
\hline \multicolumn{2}{|l|}{ Mean Age } & 21.06 Years \\
\hline \multirow{2}{*}{ Accomodation } & Hostel & 744 (87.4\%) \\
\hline & Home & 107 (12.6\%) \\
\hline \multirow{2}{*}{ Marital Status } & Single & 768 (90.2\%) \\
\hline & Married & 83 (9.8\%) \\
\hline \multirow{2}{*}{ Residence } & Urban & 38 (4.5\%) \\
\hline & Rural & 813 (95.5\%) \\
\hline \multirow{5}{*}{ Year of Study } & $1^{\text {ST }}$ YEAR & $190(22.3 \%)$ \\
\hline & $2^{\mathrm{ND}}$ YEAR & 156 (18.3\%) \\
\hline & $3^{\mathrm{RD}}$ YEAR & 190 (22.3\%) \\
\hline & $4^{\mathrm{TH}}$ YEAR & 150 (17.6\%) \\
\hline & $5^{\text {TH }}$ YEAR & 165 (19.4\%) \\
\hline \multicolumn{3}{|c|}{$\begin{array}{l}\text { Table-I. Basic demographic characteristics of study } \\
\text { group }\end{array}$} \\
\hline
\end{tabular}

\section{Anxiety \& Depression}

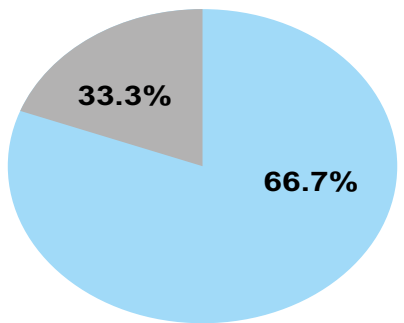

Anxiety \& Depression Normal

Figure-1. Prevalence of Anxiety \& Depression

\section{Anxiety \& Depression by MBBS Year}

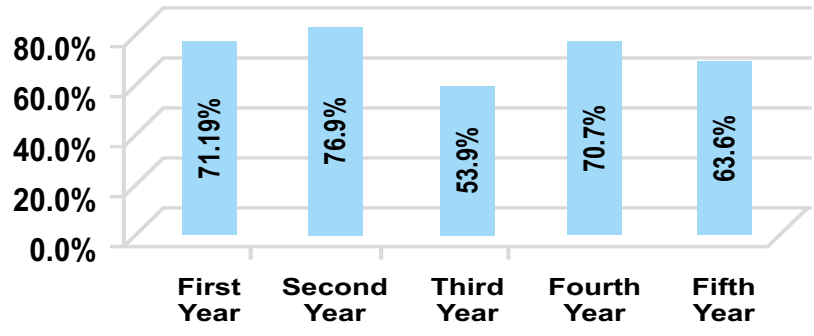

Figure-2. Frequency of Anxiety \& depression by MBBS year.

\begin{tabular}{|c|c|c|c|c|c|c|}
\hline Year of study & & First & Second & Third & Fourth & Fifth \\
\hline \multicolumn{2}{|l|}{ Mean } & 28.23 & 31.46 & 24.64 & 29.45 & 27.00 \\
\hline \multicolumn{2}{|l|}{ Std. Deviation } & 14.784 & 14.525 & 13.986 & 14.524 & 16.380 \\
\hline \multicolumn{2}{|l|}{ Median } & 24.00 & 30.00 & 20.00 & 28.00 & 25.00 \\
\hline \multirow[t]{2}{*}{ Percentiles } & 25 & 18.00 & 20.00 & 15.00 & 18.00 & 15.00 \\
\hline & 75 & 37.00 & 40.75 & 33.00 & 37.25 & 35.00 \\
\hline \multicolumn{2}{|l|}{ Minimum } & 2 & 3 & 0 & 3 & 0 \\
\hline Maximum & & 77.00 & 73.00 & 79.00 & 83.00 & 94.00 \\
\hline
\end{tabular}

\begin{tabular}{|c|c|c|c|c|c|c|c|}
\hline & & \multicolumn{4}{|c|}{ Anxiety } & \multirow{3}{*}{ Total } & \multirow{3}{*}{ P Value } \\
\hline & & \multicolumn{2}{|c|}{ Anxiety } & \multicolumn{2}{|c|}{ Normal } & & \\
\hline & & $\mathbf{N}$ & $\%$ & $\mathbf{N}$ & $\%$ & & \\
\hline \multirow{5}{*}{ MBBS Year } & First Year & 135 & $71.1 \%$ & 55 & $28.9 \%$ & 190 & \multirow{6}{*}{$<0.001^{*}$} \\
\hline & Second Year & 120 & $76.9 \%$ & 36 & $23.1 \%$ & 156 & \\
\hline & Third Year & 102 & $53.7 \%$ & 88 & $46.3 \%$ & 190 & \\
\hline & Fourth Year & 106 & $70.7 \%$ & 44 & $29.3 \%$ & 150 & \\
\hline & Fifth Year & 105 & $63.6 \%$ & 60 & $36.4 \%$ & 165 & \\
\hline \multicolumn{2}{|c|}{ Total } & 568 & & 283 & & 851 & \\
\hline
\end{tabular}




\begin{tabular}{|c|c|c|c|c|c|c|c|}
\hline & & \multicolumn{4}{|c|}{ Anxiety } & \multirow{3}{*}{ Total } & \multirow{3}{*}{ P Value } \\
\hline & & \multicolumn{2}{|c|}{ Anxiety } & \multicolumn{2}{|c|}{ Normal } & & \\
\hline & & $\mathbf{N}$ & $\%$ & $\mathbf{N}$ & $\%$ & & \\
\hline \multirow{2}{*}{ Age Groups } & $<=21$ years & 337 & $69.9 \%$ & 145 & $30.1 \%$ & 482 & \multirow{3}{*}{$0.025^{\star}$} \\
\hline & $>21$ years & 231 & $62.6 \%$ & 138 & $37.4 \%$ & 369 & \\
\hline \multicolumn{2}{|c|}{ Total } & 568 & & 283 & & 851 & \\
\hline
\end{tabular}

\begin{tabular}{|c|c|c|c|c|c|c|c|}
\hline & & \multicolumn{4}{|c|}{ Anxiety } & \multirow{3}{*}{ Total } & \multirow{3}{*}{$P$ Value } \\
\hline & & \multicolumn{2}{|c|}{ Anxiety } & \multicolumn{2}{|c|}{ Normal } & & \\
\hline & & $\mathbf{N}$ & $\%$ & $\mathbf{N}$ & $\%$ & & \\
\hline \multirow{2}{*}{ Accommodation } & Hostel & 499 & $67.1 \%$ & 245 & $32.9 \%$ & 744 & \multirow{3}{*}{$0.596^{*}$} \\
\hline & Home & 69 & $64.5 \%$ & 38 & $35.5 \%$ & 107 & \\
\hline Total & & 568 & 283 & 283 & & 851 & \\
\hline
\end{tabular}

\begin{tabular}{|c|c|c|c|c|c|c|c|}
\hline & & \multicolumn{4}{|c|}{ Anxiety } & \multirow{3}{*}{ Total } & \multirow{3}{*}{$P$ Value } \\
\hline & & \multicolumn{2}{|c|}{ Anxiety } & \multicolumn{2}{|c|}{ Normal } & & \\
\hline & & $\mathbf{N}$ & $\%$ & $\mathbf{N}$ & $\%$ & & \\
\hline \multirow[t]{2}{*}{ Marital Status } & Single & 513 & $66.8 \%$ & 255 & $33.2 \%$ & 768 & \multirow{3}{*}{$0.922^{*}$} \\
\hline & Married & 55 & $66.3 \%$ & 28 & $33.7 \%$ & 83 & \\
\hline Total & & 568 & 283 & 283 & & 851 & \\
\hline
\end{tabular}

Table-VI. Co-relation between anxiety and depression by marital Status.

\section{DISCUSSION}

As a cultural obligation women in the interior of Sindh are mainly confined within the walls of their homes. They socialize mostly on occasions of weddings or during the sad demise of a relative. Even during those occasions they are accompanied by the male members of their families. Some families may have so stringent rules that they do not allow them to go out for shopping alone nor can they communicate freely within the ambits of their neighborhood. Whenever they go out for a compelling reason wearing a hijab or 'burqa' (veil) is a must. Sending girls for normal schooling is a tough decision. Preference is usually given to a nearby 'madrasah' teaching only. While families having some skilled educational background send their girls for education outside their homes. The students belonging to these families may excel and go up to graduate and post graduate levels. This segment of women educated lot is a small proportion of the remaining rural population of Sindh at large. Setting up of medical colleges exclusively for girl students reflectsthe same mind set. Admissions in the medical colleges are based on a limited quota allocated to different rural districts. For girls having been raised and nurtured in a rural environment entering a medical university is no less than an uphill task. Given the cultural and social restraints, studying in an institution comprises of a male dominant faculty and a male dominant administrative set-up the 'academic sailing' for most of them may be dually challenging both culturally and educationally.

Since the prevalence of anxiety and depression is more common in the rural areas of Sindh ${ }^{18}$ and that the higher prevalence of anxiety and depression is reported among the female medical students ${ }^{2,3,10}$, it is expected that the female medical students belonging to the rural areas would have higher prevalence of anxiety and depression compared to those hailing from the urban areas. The same is evident in our findings. $66.7 \%$ of female medical students of our University had anxiety and depression which is strikingly higher compared to those reported among the medical students from urban Punjab $(24.37 \%)^{2}$, $\left(43.89 \%{ }^{4}\right.$, Islamabad $(39.6 \%)^{14}$ and $45.5 \%$ in a multicenter study from Lahore and 
Karachi. ${ }^{19}$ The reason for these wide differences of prevalence rates of anxiety and depression among the students of rural and urban medical institutions needs further scrutiny. Nevertheless, apart from other possible factor highlighted in previous studies such as academic stress ${ }^{10}$, lack of leisure time ${ }^{14}$, examination stress ${ }^{2}$, the higher figures in our female medical students is probably due to their predominant rural background and the concomitant cultural and social 'barriers' beings faced by them as a result of a maledominant faculty and administrative set-up. It would be reasonable to consider this aspect as an added stressor. The critical issue here is that of a communication gap. Already a vulnerable lot, they may have a hard time in asking subject related questions, clarifying difficulty terminologies and discussing the cases openly when it comes to facing a male faculty member. This in turn would make their academic grooming more strenuous. Also, they may not be assertive while resolving their administrative matters against the male office staff. The overall outcome is more likely a 'suppressed' state of affairs culminating into a depressed state of mind.

Furthermore, in urban cities the interactive environment within and outside the institution is relatively more liberal compared to the interior of Sindh which is more conservative. Before admission these female students were mainly confined to their homes and now most of the time they remain confined within the walls of their institution. The impact of this kind of restrictive environment cannot be overlooked. Interestingly, when we look at the figures relating to the accommodation it is not surprising to note that the prevalence rates of anxiety and depression do not differ significantly between the students living in homes or in hostels nor do they change due to their marital status. This lends some weight to our observation that the anxiety and depression among women in the interior of Sindh originate right from their homes and the same is carried all along with their personal, social and professional lives.

Given the urban-rural differences the situation in Karachi does not seems to support our inferences. Inam et $\mathrm{al}^{3}$ and Khan et $\mathrm{al}^{5}$ reported prevalence rates of $60 \%$ and $70 \%$ respectively in students of medical institutions at Karachi which comes within the range similar to that of ours $(66.7 \%)$. The reason for this discrepancy is likely multifaceted and debatable.

Arguably, the insecurity among medical students living in Karachi due to law and order situation, frequent acts of terrorism and fear of street crimes may have given rise to a compound affect. A report from Multan has also implicated these factors among others for increasing rates of anxiety and depression in an urban community sample. ${ }^{20}$

In our study $1^{\text {st }}$ and $2^{\text {nd }}$ year students had highest rate of anxiety and depression $(71.6 \%$ and $76.9 \%$ respectively) compared to the students of higheryears. Similar observations have been made in the previous studies. ${ }^{2,3,5,21}$ The common factor here between our and other studies appears to be the new and unfamiliar educational environment and a new study course. Understandably, these two may contribute equally for the higher prevalence rates among students of early years regardless of whether they are studying in urban or the rural institutions. As far the declining rates in later years of studies, we endorse the already published views [Alvi T et al] that the heightened levels of anxiety and depression may ease down due to gradual adaptation to the educational environment and better grasp over the study course. In our study the younger the age $(<21)$ and higher the prevalence rates projects the same scenario.

It is noteworthy that none of the students that we surveyed were taking psychotropic medications nor they have ever visited a psychiatrist before. They were punctual and were attending classes and hospital postings regularly. Whether this represents an example of self resilience or utter ignorance is open for further debate. It is likely that the social stigma attached to having been to a psychiatrist for treatment may have prevented these students from seeking the psychiatric help. In context of rural Sindh in particular, the 
revelation of this sort could possibly affect their future marriage prospects as well. We believe a proper psychiatric evaluation of these students would have shed more light on the clinical and psychobiological characteristics of these disorders in our students.

\section{CONCLUSION}

The results of our study show a high proportion of female medical students particularly those hailing from various rural districts of Sindh suffer from anxiety and depression during their educational years. Female gender, younger age and rural environment appear to have a profound negative impact. Proper psychiatric evaluation of these students is warranted so that adequate remedial measures can be undertaken where necessary.

\section{RECOMMENDATION}

Increasing the number of female faculty members especially in the medical colleges for girls would help in mitigating these problems to some extent. The services of a clinical psychologist be made available in the medical institutions so that the proper evaluation and further psychiatric referrals can be arranged.

\section{ACKNOWLEDGEMENTS}

The authors wish to thank all the medical students who spared their valuable time in participating the study.

Copyright(C) 05 Feb, 2017.

\section{REFERENCES}

1. Mirza I, Jenkins R. Risk factors, prevalence, and treatment of anxiety and depressive disorders in Pakistan: systematic review. BMJ 2004; 328(7443): 794.

2. Alvi T, Assad F, Ramzan M, Khan FA. "Depression, anxiety and their associated factors amongst medical students". J Coll Physicians Surg Pak. 2010; 20(2):122-6.

3. Inam SN, Saqib A, Alam E. Prevalence of anxiety and depression among medical students of private university. J Pak Med Assoc. Feb 2003; 53(2): 44-47.

4. Jadoon NA, Yaqoob R, Raza A, Shehzad MA, ZeshanSC. Anxiety and depression among medical students: a cross-sectional study. J Pak Med Assoc. Aug 2010; 60(8): 699-702.
5. Khan MS, Mahmood S, Badshah A, Ali SU, Jamal Y. Prevalence of depression, anxiety and their associated factors among medical students in Karachi, Pakistan. J Pak Med Assoc. Dec 2006; 56(12):583-586.

6. Rab F, Mamdou R, Nasir S. Rates of depression and anxiety among female medical students in Pakistan. East Mediterr Health J. Jan-Feb 2008; 14(1):126-133.

7. Dyrbye LN, Thomas MR, Eaker A, et al. Race, ethenicity and medical students wellbeing in the United States. Arch Intern Med. Oct 2007; 167(19):2103-09.

8. Abdulghani H. Stress and depression among medical students: A cross sectional study at a medical college in Saudi Arabia. Pak J Med Sci. 2008; 24(1): 12.

9. Talaei A, Ardani AR, Saghebi A. A survey of depression among Iranian medical students and its correlation with social support and satisfaction. J Pak Psych Soc. 2008; 5(2):90-95.

10. Al-Dabal BK, Koura MR, Rasheed P, Al-Sowielem L, Makki SM. "A comparative study of perceived Stress among female Medical and Non-medical University Students in Dammam, Saudi Arabia". Sultan Qaboos Univ Med J. 2010 Aug; 10(2):231-40.

11. Henning K, Ey S, Shaw D. Perfectionism, the imposter phenomenon and psychological adjustment in medical, dental, nursing and pharmacy students. Med Educ. Sep 1998; 32(5):456-64.

12. Kellner R, Wiggins RJ, Pathak D. Distress in medical and law students. Compr Psychiatry May 1986; $27(3): 220-3$.

13. Quince TA,Wood DF, Parker RA, Benson J. Prevalence and persistence of depression among undergraduates: a longitudinal study at one UK medical school. BMJ Open 2012; 2(4).

14. Prevalence of anxiety and depression among medical students of Shifa medical college of medicine. Abrar A, Kazim M, Hanif M, Mansoor S, Tahir S1, Makken N, Yousufzai W. PJNS. July-Sep2014; 9(3):12-15.

15. Ali BS, Amanullah S. A comparative review of two screening instruments: the Aga Khan University Anxiety and Depression Scale and the self reporting questionnaire. J Pak Med Assoc. Mar 1998; 48(3):7982.

16. Ali BS, Reza H, Khan MM, Jehan I. Development of an indigenous screening instrument in Pakistan: The Aga Khan University Anxiety and depression Scale. J Pak Med Assoc. Sep 1998; 48(9):261-5. 
17. Ali B. Validation of an indigenous screening questionnaire for anxiety and depression in an urban squatter settlement of Karachi. J Coll Physician Surg Pak.1998; 8:207-210.

18. Luni FK, Ansari B, Jawad A, Dawson A, Baig SM. Prevalence of depression and anxiety in a village in Sindh. J Ayub Med Coll Abbotabad 2009; 21(2):68-72.

19. Hashmi MA, Aftab AM, Naqvi HS, Sajjad W1, Mohsin M1, Imran S. Khawaja. Anxiety and Depression in Pakistani Medical Students: A Multi-Center
Study. Journal of Society for development in new net environment in B\&H.2014; 8(7):813-20.

20. Jadoon NA, Munir W, Choudry ZS, et al. Risk factors and prevalence of anxiety and depression in urban Multan. Nishtar Med J 2009;1(2):14-18

21. Guthrie EA, Black D, Shaw CM, Hamilton J, Creed $\mathrm{FH}$, Tomenson B. Psychological stress in medical students: a comparison of two very different university courses. Stress Med.1997; 13:179-84.

\title{
PREVIOUS RELATED STUDY
}

Khalid Hayat Khan, Mubashar Hussain Shah. ANXIETY \& DEPRESSION; COMPARATIVE STUDY OF SOMATIC SYMPTOMS BETWEEN TWO POPULATION GROUPS (Original) Prof Med Jour 10(4) 298 - 301 Oct, Nov, Dec, 2003.

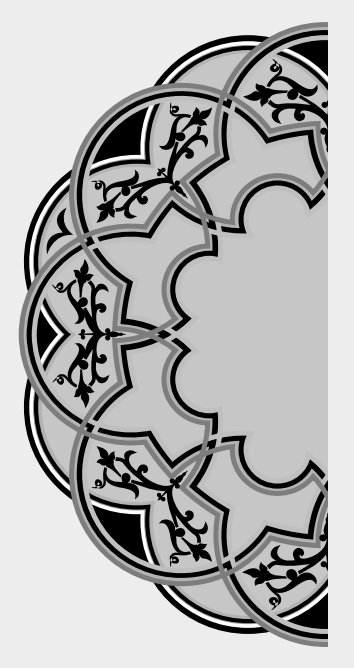

\section{"Old ways won't open new doors."}

\author{
Unknown
}

AUTHORSHIP AND CONTRIBUTION DECLARATION

\begin{tabular}{|c|l|}
\hline Sr. \# & \multicolumn{1}{|c|}{ Author-s Full Name } \\
\hline 1 & Dr. Muslim Ali Lakhiar \\
2 & Dr. Shaheen Ahmed Mughal \\
3 & Dr. Motti Ram Bhattia \\
4 & Dr. Awais Bashir larik \\
\hline
\end{tabular}

Contribution to the paper

Author $=\mathbf{s}$ Signature

Study concept, Design manuscript, Writing and review

Protoact writing, manuscript writing \& review Data collection, Data analysis, Review Data collection, Analysis and manuscript review

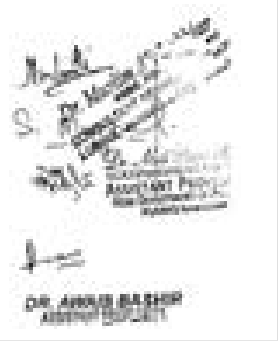

